\title{
Comparative study of Hormonal Receptor Status Discrepancy - Brain Breast Cancer Metastasectomy vs Other Localities.
}

\section{Kristýna Procházková}

Charles University Faculty of Medicine in Pilsen: Univerzita Karlova Lekarska fakulta v Plzni Josef Vodička ( $\nabla$ vodicka@fnplzen.cz)

Charles University Faculty of Medicine in Pilsen: Univerzita Karlova Lekarska fakulta v Plzni https://orcid.org/0000-0001-7540-2977

\section{Jana Horová}

Charles University Faculty of Medicine in Pilsen: Univerzita Karlova Lekarska fakulta v Plzni

\section{Petr Hošek}

Charles University Faculty of Medicine in Pilsen: Univerzita Karlova Lekarska fakulta v Plzni

\section{Radana Vrzáková}

Charles University Faculty of Medicine in Pilsen: Univerzita Karlova Lekarska fakulta v Plzni

\section{Veronika Soukupová}

Charles University Faculty of Medicine in Pilsen: Univerzita Karlova Lekarska fakulta v Plzni

\section{Martin Skála}

Charles University Faculty of Medicine in Pilsen: Univerzita Karlova Lekarska fakulta v Plzni Jakub Šebek

Charles University Faculty of Medicine in Pilsen: Univerzita Karlova Lekarska fakulta v Plzni Radek Kučera

Charles University Faculty of Medicine in Pilsen: Univerzita Karlova Lekarska fakulta v Plzni Jiř́ Dostál

Charles University Faculty of Medicine in Pilsen: Univerzita Karlova Lekarska fakulta v Plzni

\section{Vladimír Přibáň}

Charles University Faculty of Medicine in Pilsen: Univerzita Karlova Lekarska fakulta v Plzni

\section{Ondřej Hes}

Charles University Faculty of Medicine in Pilsen: Univerzita Karlova Lekarska fakulta v Plzni

\section{Tomáš Svoboda}

Charles University Faculty of Medicine in Pilsen: Univerzita Karlova Lekarska fakulta v Plzni Jindřich Fínek

Charles University Faculty of Medicine in Pilsen: Univerzita Karlova Lekarska fakulta v Plzni

\section{Vladislav Třeška}

Charles University Faculty of Medicine in Pilsen: Univerzita Karlova Lekarska fakulta v Plzni 


\section{Research Article}

Keywords: breast cancer, breast cancer metastases, hormone receptor status, metastasectomy, receptor status discrepancy

Posted Date: May 19th, 2021

DOl: https://doi.org/10.21203/rs.3.rs-517927/v1

License: (c) (i) This work is licensed under a Creative Commons Attribution 4.0 International License.

Read Full License 


\section{Abstract}

Purpose: Hormonal receptor (HR) status is one of the key factors when determining the treatment of breast cancer. Even though HR conversion is one of the most researched topics recently, most of the previous studies include only the results of biopsies instead of samples obtained by metastasectomy.

Aim: The aim of this study is to compare the occurrence of HR status conversion in brain breast cancer metastatic tissue to other localities.

Methods: A total of 50 patients after breast cancer metastasectomy of brain, lung or liver were included in the study. The clinical characteristics were recorded.

Results: HR conversion was observed in a total of 30 cases $(60.0 \%)$, while HER2 (human epidermal growth factor receptor 2) discrepancy occurred only in one case (2.0\%). Endocrine therapy significantly contributed to the decrease progesterone and estrogen receptor expression in metastatic tissue compared to the primary tumor $(p=0.009, p=0.023$; respectively). Triple negativity was more common in the brain metastases $(p=0.039)$. Liver metastases occurred in significantly younger patients $(p=0.034)$, however brain metastases had the poorest OS $(p=0.007)$.

Conclusion: HR conversion occurs in more than $50 \%$ of cases of breast cancer metastatic disease, while HER2 discrepancy is rare. Hormonal therapy significantly contributes to the decrease of HR positivity in metastases. Triple negativity is more common in the brain metastases than in other localities. Brain metastases of breast cancer are associated with the poorest prognosis.

\section{Introduction}

Prognosis of metastatic breast cancer $(\mathrm{BC})$ patients is generally poor. Systematic treatment for primary and metastatic $B C$ is based on the estrogen receptor (ER), progesterone receptor (PR) and human epidermal growth factor receptor 2 (HER2) status.

The National Comprehensive Cancer Network (NCCN) guidelines recommend a biopsy of the first site of recurrence for recurrent or stage IV disease along with the measurement of the ER, PR, and HER2 status [1]. Also the European School of Oncology International Consensus Guidelines for advanced BC also recommend to biopsy the metastatic lesion to confirm the diagnosis, particularly when a metastasis is diagnosed for the first time [2]. However, routine immunohistochemical investigation of metastatic lesions, especially of brain metastatic lesions, is still not a part of the standard workflow. Therefore, indication for of endocrine or HER2-targeted therapies is mainly directed by the biomarker status of the primary tumor.

Several studies have shown a lack of stability of the hormonal receptors (HR) and HER2 between the primary tumor and its metastases [3-11]. Even though HR conversion has been one of the most researched topics recently, the studies are highly heterogeneous in terms of differences in staining 
protocols, influence of various systematic therapies, use of different cut-off values for positivity ( $1 \%$ vs $10 \%$ for ER and PR), and also in the quality of the studied sample. As the receptor studies can be performed not only on the basis of surgical resection, but also on core biopsy or fine-needle aspiration of either primary or metastatic lesions, a false-negative receptor status may be obtained due to the intratumoral heterogeneity of receptor expression, which is well-characterized in breast cancer [8].

The aim of this study is to compare receptor profiles between primary BC lesions and its metastases to brain, lung and liver. We excluded material obtained by fine-needle aspiration or core cut biopsy. Our study is based strictly on tissue samples obtained by mastectomy or partial resection of the breast, or by metastasectomy of the liver, lung or brain. The association between receptor conversion and prognostic outcomes in these patients was also analyzed.

This is the first study of this type performed in the Czech population with a high objectivity due to the use the same methodology in a single center.

\section{Methods}

The study sample consisted of patients surgically treated for a primary BC tumor with subsequent BC metastasectomy at the Department of Surgery or Department of Neurosurgery, University Hospital in Pilsen, in the time period January 2000 - January 2019.

The clinical characteristics - histopatological stage, tumor grade, immunohistochemical factors, time to progression (defined as the time period between curative surgery of the breast and first detection of metastatic disease), metastatic tissue data (size of the largest metastasis, number of metastatic lesions, type of surgery, number of procedures, histopathology results), oncological treatment and follow-up data were recorded.

\section{Immunohistochemical Analyses}

All immunohistochemistry $(\mathrm{IHC})$ staining were performed at a single laboratory (University Hospital Pilsen), using a Ventana Benchmark XT automated stainer (Ventana Medical System, Inc., Tucson, AZ, USA). The following primary antibodies were used: estrogen receptor (monoclonal, clone Sp1, Ventana, RTU), progesterone (monoclonal, clone IE2, Venata), Ki-67 (monoclonal, clone MIB1, Venata), HER-2/neu (monoclonal, clone 4B5, Ventana, RTU), and e-cadherin (monoclonal, clone EP6, Biocare Medical, Concord, CA, 1:1000). Primary antibodies were visualized using a supersensitive streptavidin-biotinperoxidase complex (BioGenex). Internal biotin was blocked using the standard protocol for the Ventana Benchmark XT automated stainer (hydrogen peroxide-based). Appropriate positive and negative controls were also used. Percentage of positive cells was estimated. For ER, PR and Ki-67, only nuclear positivity was considered as a positive staining. For E-cadherin and HER-2/neu, only membranous positivity was considered a positive result. The intensity of staining was compared with positive internal (if available) and external control. 
Samples with $1 \%$ or greater reactivity were defined as positive for both ER and PR receptors. HER2 overexpression was defined as a membrane staining score of 3+ (HER2+).

\section{Statistical analysis}

HR receptor findings were analyzed both quantitatively (staining percentage) and after classification to the positive/negative status. Time to progression (TTP), progression-free survival (PFS) and overall survival (OS) after surgical treatment of the primary tumor were selected as treatment outcome indicators and analysed in relation to the clinical characteristics. TTP was defined from the time of the primary tumor surgery to the diagnosis of the metastatic disease. PFS was defined from the time of metastasectomy to the time of the first recurrence diagnosis or death. OS was defined from the time of the surgical treatment of the primary tumor to the time of death. Since TTP had no censored observations (given by the sample definition), it was analyzed as a regular continuous variable using nonparametric methods. The relationships between continuous variables and PFS/OS were analysed using univariable Cox proportional hazards model. When existing relationship was indicated, a threshold (cut-off) value for the continuous variable was determined by an automated optimization process finding the threshold value providing the lowest Cox-Mantel p-value after Kaplan-Meier analysis. Categorical factors of survival were analysed using the Kaplan-Meier method with Gehan-Wilcoxon test. 1- and 3-yr survival rates and survival medians were calculated by linear interpolation of the appropriate Kaplan-Meier survival curve estimation, the median follow-up was determined by the inverse Kaplan-Meier method of OS data. Mutual relationships of continuous variables were analyzed using Kendall's tau, associations of continuous and categorical variables were investigated by means of Mann-Whitney $U$ test and Kruskal-Wallis ANOVA, and mutual dependencies of categorical variables were tested with Fisher's exact test. Statistical analysis was performed in STATISTICA (version 11Cz, TIBCO Software Inc., Palo Alto, CA, USA) and Matlab (version 2019b, The MathWorks, Inc., Natick, MA, USA). All reported p values are 2-tailed and the level of statistical significance was set at $a=0.05$.

False discovery rate (FDR) was controlled by means of the Benjamini-Hochberg procedure, obtaining an FDR estimate of $30 \%$ at the set a of 0.05 . In order to achieve a conservative overall FDR of $5 \%$, a would have to be decreased to 0.0013 .

\section{Results}

Overall, 50 patients were included in the study. 30 patients underwent brain metastasectomy, 10 patients underwent liver resection and 10 patients lung surgery for histological verification of breast cancer metastases. Basic characteristics of the patients are shown in Table 1. 
Table 1

Basic characteristics of the patients.

\section{Characteristics}

Patient

Female

Age (years) - breast surgery

Median [min - max]

Histology of primary tumour

DIC

LIC

Other

Size of the primary tumor ( $\mathrm{mm}$ )

Median [min - max]

TNM stage at diagnosis

Tis

T1a

T1b

$\mathrm{T} 1 \mathrm{c}$

$\mathrm{T} 2$

T3

$\mathrm{T} 4$

NO

N1

N2

N3

N4

MO

M1 n (\%)

$50(100.0)$

51.9 [25.9-78.5]

39 (78.0)

2 (4.0)

7 (14.0)

20 [4.0-90.0]

$2(4.0)$

0 (0)

2 (4.0)

18 (36.0)

$24(48.0$

1 (2.0)

$3(6.0)$

26 (52.0)

15 (30.0)

5 (10.0)

4 (8.0)

$0(0)$

1 (2.0)

49 (98.0)

DIC - ductal invasive carcinoma; LIC - lobular invasive carcinoma; RFA -radiofrequency ablation; TTP - time to progression (time to progression after breast surgery), PFS - progression-free survival (time to progression after metastasectomy); OS - overall survival 


\section{Characteristics}

TTP (months)

Median $[95 \% \mathrm{Cl}]$

Age (years) - metastasectomy

Median [min - max]

PFS (months)

Median $[95 \% \mathrm{Cl}]$

OS (months)

Median [95\%Cl]

$54.6[42.6-93.0]$

DIC - ductal invasive carcinoma; LIC - lobular invasive carcinoma; RFA -radiofrequency ablation; TTP - time to progression (time to progression after breast surgery), PFS - progression-free survival (time to progression after metastasectomy); OS - overall survival

TTP had no association with the site of the metastases, but it was significantly related to PR staining intensity in metastases $(p=0.027)$, and to the expression of ER in both the primary tumor and metastases $(p=0.028, p=0.017$; respectively). Higher percentage of hormonal receptors positivity was always associated with longer TTP.

We observed conversion of PR receptor status between the primary tumor and metastases in 26 cases (52.0\%), of which 15 cases (30.0\% overall) converted from positivity to negativity, and 11 cases $(22.0 \%)$ from negativity to positivity. ER conversion was found in 13 cases $(26.0 \%), 11(22.0 \%)$ of which were from positivity to negativity, and $2(4.0 \%)$ from negativity to positivity. Overall, 30 of cases $(60.0 \%)$ changed their HR profile in at least one of the receptors. 9 cases showed conversion of both receptors $(18.0 \%)$. The probability of conversion was not significantly affected by the location of the metastases. OS was not significantly affected by conversion of the estrogen or progesterone receptors- Fig. 1.

Comparison of the receptor expression between the primary tumor and metastases is provided in Table 2, 3. 
Table 2

Rate of discrepancy according to the site of the metastases and direction of conversion.

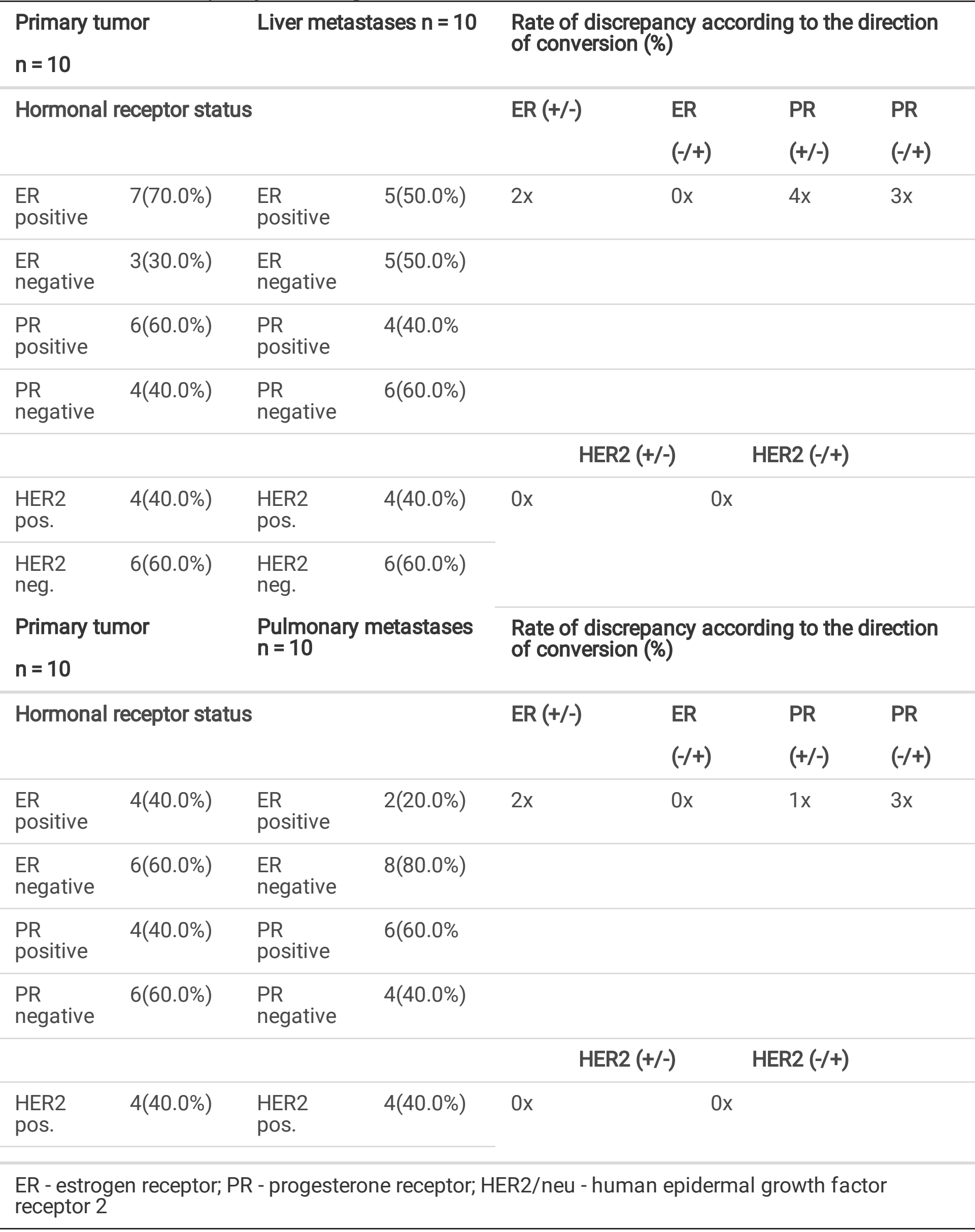




\begin{tabular}{|c|c|c|c|c|c|c|c|}
\hline \multicolumn{2}{|c|}{$\begin{array}{l}\text { Primary tumor } \\
n=10\end{array}$} & \multicolumn{2}{|c|}{ Liver metastases $n=10$} & \multicolumn{4}{|c|}{$\begin{array}{l}\text { Rate of discrepancy according to the direction } \\
\text { of conversion (\%) }\end{array}$} \\
\hline $\begin{array}{l}\text { HER2 } \\
\text { neg. }\end{array}$ & $6(60.0 \%)$ & $\begin{array}{l}\text { HER2 } \\
\text { neg. }\end{array}$ & $6(60.0 \%)$ & & & & \\
\hline \multicolumn{2}{|c|}{$\begin{array}{l}\text { Primary tumor } \\
n=30\end{array}$} & \multicolumn{2}{|c|}{$\begin{array}{l}\text { Brain metastases } n= \\
30\end{array}$} & \multicolumn{4}{|c|}{$\begin{array}{l}\text { Rate of discrepancy according to the direction } \\
\text { of conversion (\%) }\end{array}$} \\
\hline \multirow{2}{*}{\multicolumn{4}{|c|}{ Hormonal receptor status }} & ER (+/-) & ER & PR & PR \\
\hline & & & & & $(-/+)$ & $(+/-)$ & $(-/+)$ \\
\hline $\begin{array}{l}\text { ER } \\
\text { positive }\end{array}$ & $11(36.7 \%)$ & $\begin{array}{l}\text { ER } \\
\text { positive }\end{array}$ & $6(20.0 \%)$ & $7 x$ & $2 x$ & $10 x$ & $6 x$ \\
\hline $\begin{array}{l}\text { ER } \\
\text { negative }\end{array}$ & $19(63.3 \%)$ & $\begin{array}{l}\text { ER } \\
\text { negative }\end{array}$ & $24(80.0 \%)$ & & & & \\
\hline $\begin{array}{l}\text { PR } \\
\text { positive }\end{array}$ & $11(36.7 \%)$ & $\begin{array}{l}\text { PR } \\
\text { positive }\end{array}$ & $7(23.3 \%$ & & & & \\
\hline \multirow[t]{2}{*}{$\begin{array}{l}\text { PR } \\
\text { negative }\end{array}$} & 19(63.3\%) & $\begin{array}{l}\text { PR } \\
\text { negative }\end{array}$ & $23(76.6 \%)$ & & & & \\
\hline & & & & \multicolumn{2}{|c|}{ HER2 (+/-) } & $\mathrm{R} 2(-/+)$ & \\
\hline $\begin{array}{l}\text { HER2 } \\
\text { pos. }\end{array}$ & $9(30.0 \%)$ & $\begin{array}{l}\text { HER2 } \\
\text { pos. }\end{array}$ & 10(33.3\%) & \multirow[t]{2}{*}{$0 x$} & \multirow{2}{*}{\multicolumn{2}{|c|}{$1 x$}} & \\
\hline $\begin{array}{l}\text { HER2 } \\
\text { neg. }\end{array}$ & $21(70.0 \%)$ & $\begin{array}{l}\text { HER2 } \\
\text { neg. }\end{array}$ & $20(66.6 \%)$ & & & & \\
\hline
\end{tabular}


Table 3

Total rate of discrepancy.

\begin{tabular}{|c|c|c|c|c|}
\hline & & Meta + & Meta - & Total \\
\hline \multirow[t]{3}{*}{ PR } & $\mathrm{BC}+$ & $6(12 \%)$ & $15(30 \%)$ & 21 \\
\hline & $B C-$ & 11 (22\%) & $18(36 \%)$ & 29 \\
\hline & Total & 17 & 33 & \\
\hline \multirow[t]{3}{*}{ ER } & $\mathrm{BC}+$ & $11(22 \%)$ & $11(22 \%)$ & 22 \\
\hline & $B C-$ & $2(4 \%)$ & $26(52 \%)$ & 28 \\
\hline & Total & 13 & 37 & \\
\hline
\end{tabular}

Patients who had received hormonal therapy for their HR-positive primary tumor showed a significantly bigger decrease of progesterone and estrogen receptor levels between the primary tumor and metastatic tissue ( $p=0.009, p=0.023$; respectively), in comparison with the patiens with primary tumors positive for the respective HR who had not received the therapy.

HER2 discrepancy was identified only in one case (2.0\%). PFS after metastasectomy was shorter in patients with HER2-positive primary tumors $(p=0.023)$ as well as metastases $(p=0.013)$. PFS after metastasectomy was significantly affected by triple negativity of the primary tumor, with longer PFS in case of triple negativity of the primary tumor - Fig. 1.

The ER pos/pos group showed low presence of E3 ubiquitin-protein ligase MIB1 (MIB1), while the ER neg/neg group had a high abundance of MIB1. High MIB1 levels were also significantly associated with lower age at the time of metastasectomy $(p=0.015)$, with lower PR and ER in the primary tumor $(p=$ $0.019, p=0.025$; respectively), and with lower ER in metastases $(p<0.001)$.

Overall survival (OS) after surgical treatment of the primary tumor was 54.6 months with median of follow-up 235.0 months. 1-year OS was $96.14 \%$ (90.82-101.46) and 3-years OS was 69.79\% (56.9582.63). OS and PFS depended strongly on TTP $(p=0.000, p=0.008$; respectively), with longer TTP leading to longer the OS and PFS. Each month of TTP extension decreases the risk of death by $5.6 \%$. PFS was also significantly longer $(p=0.020)$ in patients with higher age at the time of the metastasectomy. While liver metastases were found in significantly younger patients $(p=0.034)$, patients with brain metastases had the poorest OS $(p=0.007)$ with the most common occurrence of triple negativity in metastatic tissue $(p=0.039)$.

\section{Discussion}


Prescription of endocrine or HER2-targeted therapy for metastatic BC is still mainly determined by the biomarker status of the primary tumor, although previous studies have shown that receptor conversion is a relatively common phenomenon [3,5-11]. These observations have been, however, considered to originate from technical limitations of the method rather than representing true changes in the tissue phenotype, and mostly disregarded. Still, limited accuracy and reproducibility of receptor assays does not explain cases where receptor expression changes from 0 to $100 \%$ and vice-versa. It seems that the whole issue is much more complicated with a possible role of intratumoral heterogeneity [13], receptor conversion is thought to be the a result of clonal selection or selective pressure of therapy [14].

The rate of discrepancy for estrogen receptor reported in the literature is $6-18 \%$, for progesterone receptor it is $25-42 \%$, and $4-17 \%$ for HER2 $[3,5-9,11,12]-$ Table 4 . However, the studies are heterogeneous, especially with regard to the tissue samples studied and the processing technology used. Somewhat different results may be given by the fact that some authors also included only biopsies in the study, which may not be sufficiently objective.

Table 4

The reported rates for discordance of HR between primary and metastatic breast cancer $[3,5-9,11,12]$.

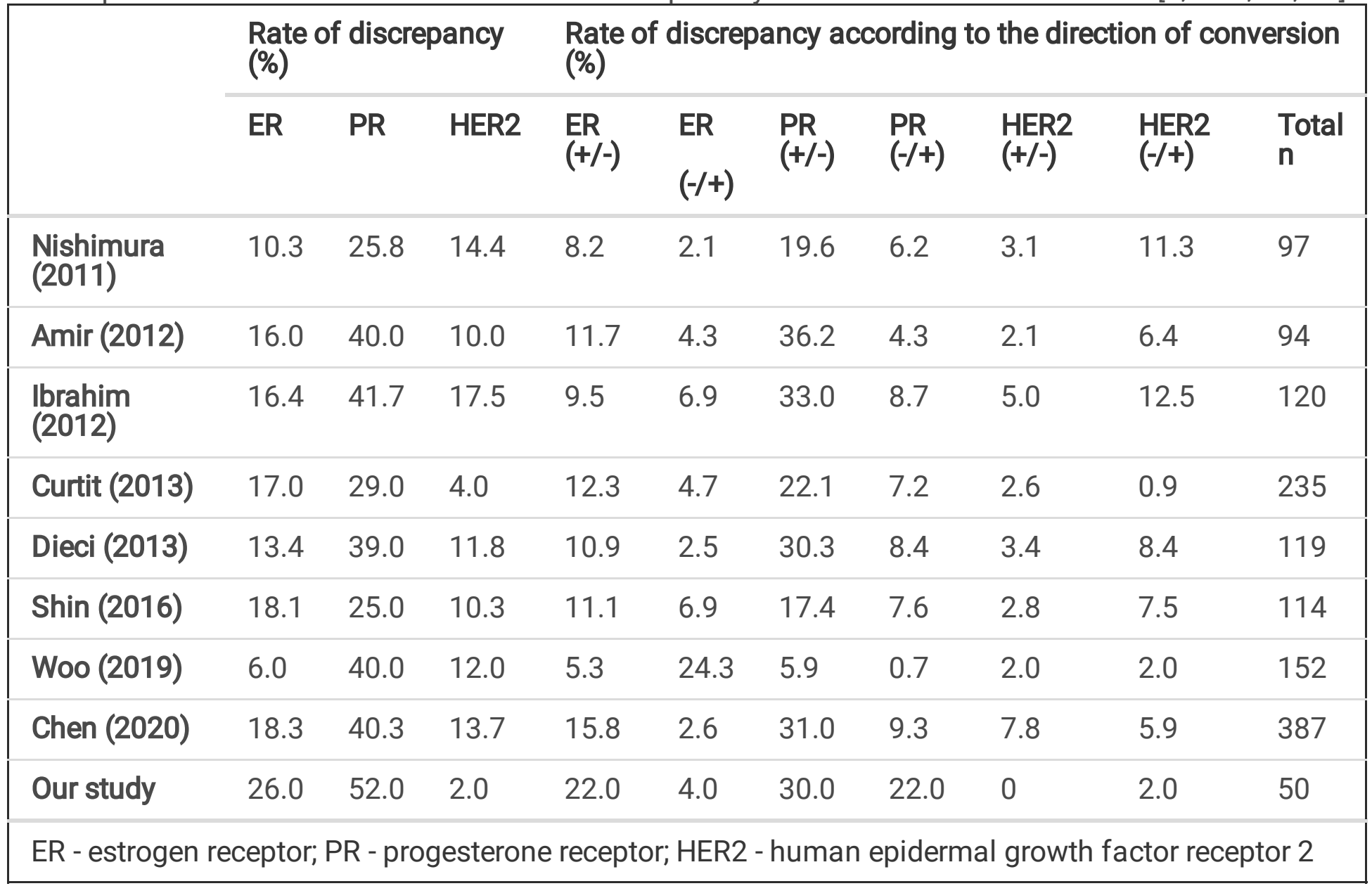

Most studies agree that the discordance is significantly higher for PR when compared with ER and HER2 and also that the conversions occurred mostly as a switch from positive to negative receptor status when compared with that from negative to $[3-9,12,15]$, while most studies consistently show more patients 
gaining HER2 expression than loosing it among the cases of HER2 expression discordance $[3,5,6,9,10$, 8].

Also in our cohort, positivity in the primary lesion and negativity in the recurrence site was a more frequent pattern than the opposite for ER and PR. Although, we observed conversion in HER2 receptor only in one case in our cohort, it was just conversion from negativity to positivity.

In their meta-analysis including 39 studies, Schrijver et al. [16] found that ER discordance was statistically significantly higher in metastases located in the central nervous system and bones compared with liver metastases, and PR discordance was higher in bone and liver metastases compared with CNS metastases. PR conversion from positivity to negativity occurred statistically significantly more often than from negativity to positivity.

Completely different results were reported by Woo et al. [11]. Although they showed, similarly to others, that negative conversion occurred more frequently than positive conversion in hormone receptors, they found no changes in ER, PR, or HER2 status in brain metastases. Also in lung metastases, no changes in ER status were observed. All primary triple-negative breast cancers remained triple-negative in the metastatic lesion in their cohort.

In contrast, Jung et al. [17] described discordances in ER, PR, and HER2 between primary tumor and resected brain metastases in more than $50 \%$ of the 37 Korean patients included in their study.

In our study, we observed the majority of conversions in brain metastases, where the transition to triple negativity was also substantially more common. However, we have not shown that the probability of conversion varies according to the location of the metastases.

Our study also confirms that endocrine therapy reduces the positivity of PR and ER receptors in metastatic tissue relatively to their original abundance in the primary lesion. In accordance with Chen et al., who reported a majority of conversions being from a positive to negative status, this may be largely attributed to selective killing of BC cells overexpressing ER or HER2 by endocrine or HER2-targeted therapy.

Hoefnagel et al. [4] hypothesized that their observation of decreased survival in patients converting to negative in their metastases may be because the endocrine treatment of stage IV disease was initiated based on the primary tumor characteristics, while the receptor-negative cells, that were actually constituting the metastases, are known to be fully resistant to endocrine treatment. Therefore, it would be important to know upfront which receptor-positive patients are likely to develop receptor-negative metastases. This would allow, for example, for a supplementation of their adjuvant hormonal therapy (to control their receptor-positive metastatic cells) with adjuvant chemotherapy. In their cohort, OS of patients showing conversion from positive to negative ER or PR, or from negative to positive ER or PR, or remaining receptor-negative was comparable, and significantly worse than that of patients remaining 
receptor-positive. ER or PR receptor conversion from positive in the primary BC to negative in distant metastases has negative prognostic value [4].

Similarly, the results of a recent study by Chen et al. [8] show that a positive ER status, not considering if in primary or metastatic $\mathrm{BC}$, was associated with a prolonged metastases-free survival when compared with ER-negative primary tumors without conversion. Furthermore, a positive ER status in breast cancer metastatic tissue regardless of the primary tumor was associated with superior OS when compared with an ER-negative tumor without conversion.

Shin et al. [10] reported that patients with concordant ER or PR positivity or discordant ER or PR status had a significantly longer post-recurrence survival than those with respective concordant negativity between the primary lesion and recurrence site.

Also, survival analyses by Woo et al. [11] indicated that a positive-to-negative conversion of ER was an independent poor prognostic factor in patients with primary ER-positive breast cancer. Identically, Dieci et al. [9] reported that patients with ER loss in recurrence had poor OS, whereas those with PR did not.

Bachmann et al. [18] found that PR and HER2 discordance correlated to shortened interval to metastasis. Aurilio et al. [19] reported that the time interval did not statistically significantly affect the discordance rate for ER, PR, or HER2.

According to our results, the higher percentage of hormonal receptors positivity in metastatic tumor correlated with the longer time to progression. However, PFS after mastectomy was shorter in case of HER2 positivity of metastatic tissue, which is confirmed with the results of our previous study [20].

Loss of HR or MIB1 seemed to be associated with a poor prognosis, too [21]. High MIB1 levels in primary lesion are known to be associated with the growth and invasion of BC. The study by Ibrahim et al. [6] showed that patients with MIB1 $\geq 20 \%$ had a significantly poorer median PFS than those with MIB1 < $20 \%$. According to our study, the higher the MIB1, the lower the expression of hormone receptors, however we did not observe significant effect of MIB1 on OS.

In summary, hormonal receptor status should always be investigated at the time of diagnosis of metastatic disease before deciding about its treatment. IHC evaluation of metastases for receptor status may change treatment decisions for patients with metastatic breast cancer. In cases of positive-tonegative conversion, hormone therapy should be discontinued to avoid unnecessary side effects of the treatment. While the probability of hormone receptor conversion in distant $\mathrm{BC}$ metastases is almost $60 \%$, conversion of HER2 neu should remain stable.

This is the first study comparing receptor profiles between primary BC lesions and its metastases to the brain, lung and liver in Czech population. Moreover, this study includes exclusively tissue samples obtained by mastectomy or partial resection of the breast and samples obtained by metastasectomy. We consider this a big positive as mere biopsy is to be considered not objective due to the well-known heterogeneity of the tumor. Also, presenting a single-institution analysis, we were able to provide more 
detailed and specific data thanks to strictly uniform processing technique, which is usually not possible with a large pooled literature review.

\section{Declarations}

Funding: This study was supported by the grant SVV-2020-2022 No 260539, by the Charles University Research Fund (Progres Q39), the grant of Ministry of Health of the Czech Republic - Conceptual Development of Research Organization (Faculty Hospital in Pilsen - FNPI 00669806) and by the Centrum of Clinical and Experimental Liver Surgery project UNCE/MED/006.

Conflicts of Interest: The authors have no conflicts of interest to declare.

Code availability: 'Not applicable' for that section.

Authors' contributions: K.P. and J.V.: project development, data collection, data analysis, manuscript writing; P.H.: statistical analysis, manuscript writing; V.T., O.H., J.F., V.P. and T.S.: critical revision; J.H., R.V., V.S., M.S., J.Š., R.K. and J.D.: data collection.

Ethics approval: All procedures performed in studies involving human participants were in accordance with the ethical standards of the institutional and/or national research committee and with the 1964 Helsinki declaration and its later amendments or comparable ethical standards.

\section{References}

1. Gradishar WJ, Anderson BO, Abraham J et al (2020) Breast Cancer, Version 3.2020, NCCN Clinical Practice Guidelines in Oncology. J Natl Compr Canc Netw. https://doi.org/10.6004/jnccn.2020.0016

2. Cardoso F, Paluch-Shimon S, Senkus E et al (2020) 5th ESO-ESMO international consensus guidelines for advanced breast cancer (ABC 5). Ann Oncol 31(12):1623-1649. https://doi.org/10.1016/j.annonc.2020.09.010

3. Nishimura R, Osako T, Okumura Y et al (2011) Changes in the ER, PgR, HER2, p53 and Ki-67 biological markers between primary and recurrent breast cancer: discordance rates and prognosis. World Journal of Surgical Oncology 9:131. https://doi.org/10.1186/1477-7819-9-131

4. Hoefnagel LDC, van de Vijver MJ, van Slooten H-J et al (2010) Receptor conversion in distant breast cancer metastases. Breast Cancer Res 12:R75-R75. https://doi.org/10.1186/bcr2645

5. Amir E, Miller N, Geddie W et al (2011) Prospective Study Evaluating the Impact of Tissue Confirmation of Metastatic Disease in Patients With Breast Cancer. JCO 30:587-592. https://doi.org/10.1200/JC0.2010.33.5232

6. Ibrahim T, Farolfi A, Scarpi E et al (2013) Hormonal Receptor, Human Epidermal Growth Factor Receptor-2, and Ki67 Discordance between Primary Breast Cancer and Paired Metastases: Clinical Impact. Oncology 84:150-157. https://doi.org/10.1159/000345795 
7. Curtit E, Nerich V, Mansi L et al (2013) Discordances in estrogen receptor status, progesterone receptor status, and HER2 status between primary breast cancer and metastasis. Oncologist 18(6):667-674. https://doi.org/10.1634/theoncologist.2012-0350

8. Chen R, Qarmali M, Siegal GP et al (2020) Receptor conversion in metastatic breast cancer: analysis of 390 cases from a single institution. Mod Pathol 33:2499-2506. https://doi.org/10.1038/s41379020-0615-z

9. Dieci MV, Barbieri E, Piacentini F et al (2013) Discordance in receptor status between primary and recurrent breast cancer has a prognostic impact: a single-institution analysis. Ann Oncol 24(1):101108. https://doi.org/10.1093/annonc/mds248

10. Shin HC, Han W, Moon HG et al (2016) Patients with Concordant Triple-Negative Phenotype between Primary Breast Cancers and Corresponding Metastases Have Poor Prognosis. J Breast Cancer $19: 268-274$

11. Woo JW, Chung YR, Ahn S et al (2019) Changes in Biomarker Status in Metastatic Breast Cancer and Their Prognostic Value. J Breast Cancer 22:439-452

12. Shin T, Duddalwar VA, Ukimura O et al (2017) Does Computed Tomography Still Have Limitations to Distinguish Benign from Malignant Renal Tumors for Radiologists? Urol Int 99:229-236

13. Allott EH, Geradts J, Sun X et al (2016) Intratumoral heterogeneity as a source of discordance in breast cancer biomarker classification. Breast Cancer Res 18:68. https://doi.org/10.1186/s13058016-0725-1

14. Perez EA, Suman VJ, Davidson NE et al (2006) HER2 Testing by Local, Central, and Reference Laboratories in Specimens From the North Central Cancer Treatment Group N9831 Intergroup Adjuvant Trial. JCO 24:3032-3038. https://doi.org/10.1200/JC0.2005.03.4744

15. Capitanio U, Bensalah K, Bex A et al (2019) Epidemiology of Renal Cell Carcinoma. Eur Urol 75:7484. https://doi.org/10.1016/j.eururo.2018.08.036

16. Schrijver WAME, Suijkerbuijk KPM, van Gils CH et al (2018) Receptor Conversion in Distant Breast Cancer Metastases: A Systematic Review and Meta-analysis. JNCl: Journal of the National Cancer Institute 110:568-580. https://doi.org/10.1093/jnci/djx273

17. Jung J, Lee SH, Park M et al (2018) Discordances in ER, PR, and HER2 between primary breast cancer and brain metastasis. Journal of Neuro-Oncology 137:295-302. https://doi.org/10.1007/s11060-017-2717-0

18. Bachmann C, Grischke EM, Staebler A et al (2013) Receptor change-clinicopathologic analysis of matched pairs of primary and cerebral metastatic breast cancer. J Cancer Res Clin Oncol 139:19091916. https://doi.org/10.1007/s00432-013-1511-4

19. Aurilio G, Disalvatore D, Pruneri G et al (2014) A meta-analysis of oestrogen receptor, progesterone receptor and human epidermal growth factor receptor 2 discordance between primary breast cancer and metastases. Eur J Cancer 50(2):277-289. https://doi.org/10.1016/j.ejca.2013.10.004

20. Procházková K, Pivovarčíková K, Roušarová M et al (2021) Prognostic Factors After Surgical Treatment of Liver Metastases from Breast Cancer - 19 Years of Experience. In Vivo 35:417-422. 
https://doi.org/10.21873/invivo.12273

21. Yamanouchi K, Kuba S, Eguchi S (2020) Hormone receptor, human epidermal growth factor receptor2, and Ki-67 status in primary breast cancer and corresponding recurrences or synchronous axillary lymph node metastases. Surg Today 50:657-663. https://doi.org/10.1007/s00595-019-01831-8

22. Yamanouchi K, Kuba S, Eguchi S (2020) Hormone receptor, human epidermal growth factor receptor2, and Ki-67 status in primary breast cancer and corresponding recurrences or synchronous axillary lymph node metastases. Surg Today 50:657-663. https://doi.org/10.1007/s00595-019-01831-8

23. Legend

\section{Figures}
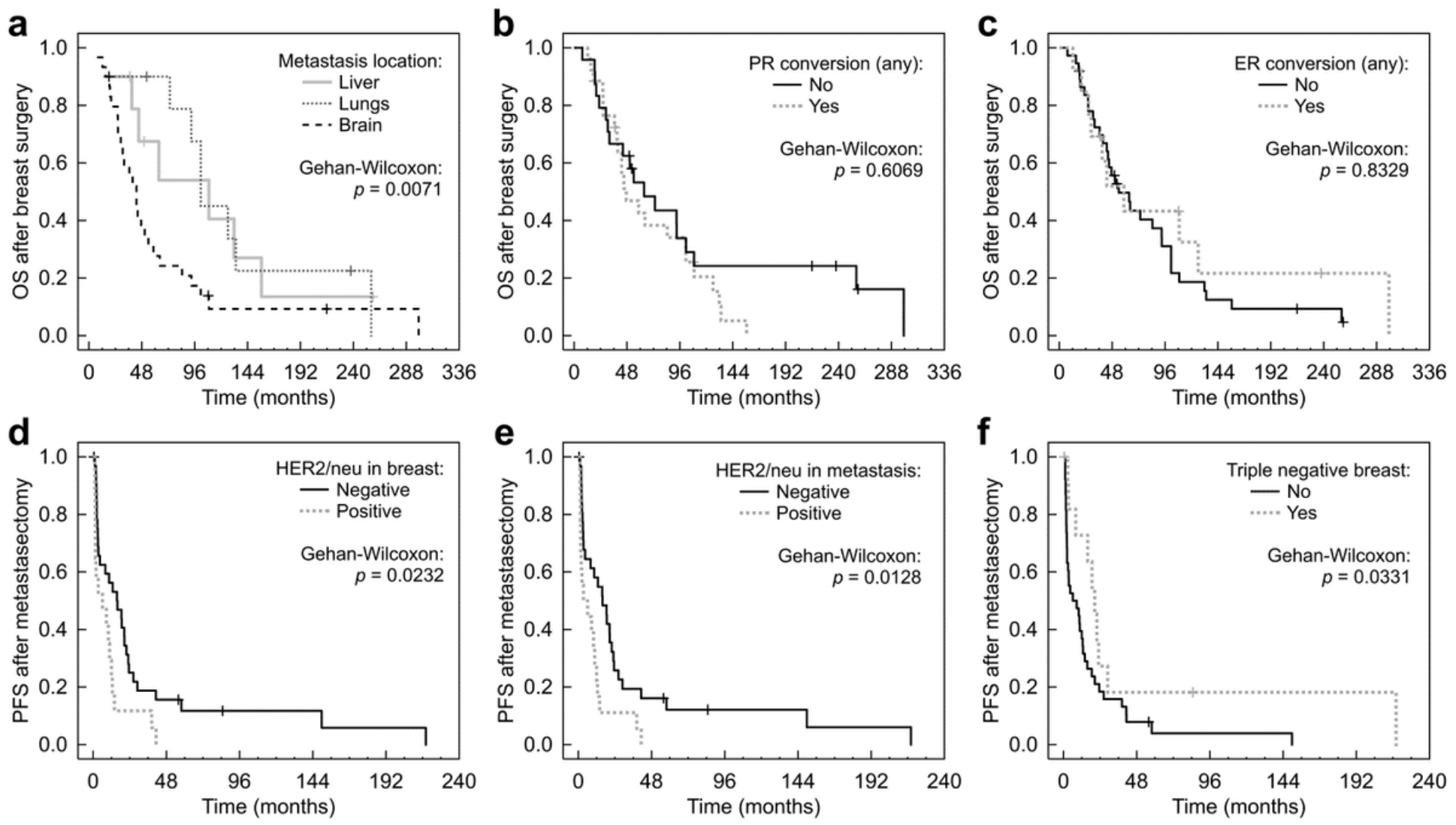

\section{Figure 1}

Kaplan-Meier plots of OS after patient stratification according to location of the metastasis: Brain metastases had significantly the poorest OS (a); according to receptor conversion: OS was not significantly affected by conversion of the ER or PR (b-c). PFS after metastasectomy was shorter in patients with HER2 expression in the primary tumor (d) as well as in metastases (e). PFS after metastasectomy was significantly affected by triple negativity of the primary tumor, with longer PFS in case of triple negativity of the primary tumor. OS, overall survival; PFS, progression-free survival; ER, estrogen receptor; PR, progesterone receptor. 